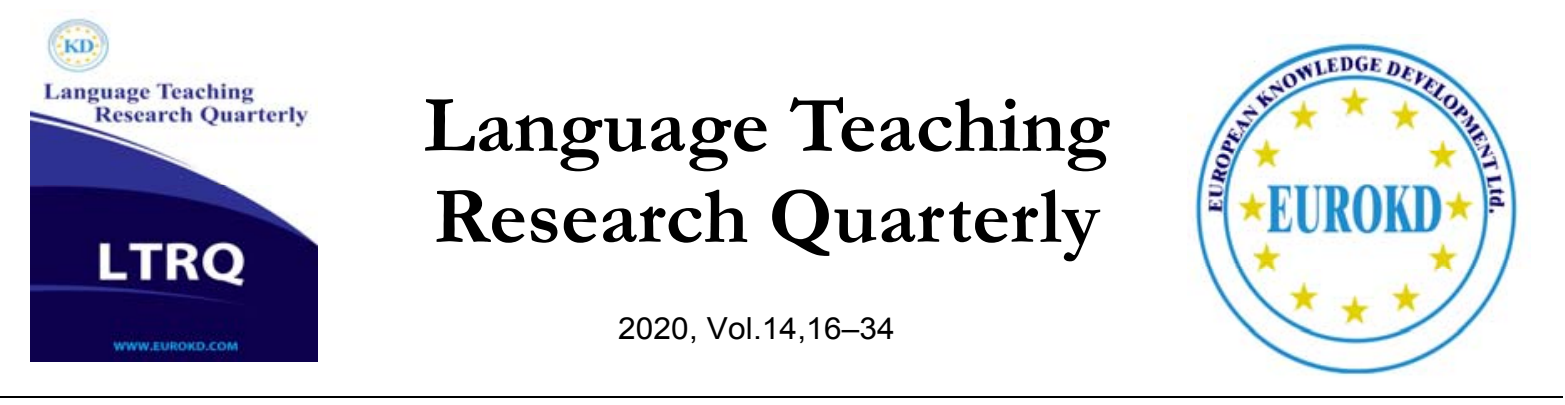

\title{
Exploring the EAP needs of students of knowledge and information science: $A$ triangulated study in Iranian EFL context
}

\author{
Behruz Lotfi Gaskaree \\ University of Zabol, Iran
}

Received 02 May 2019 Accepted 10 November 2019

\begin{abstract}
Given the lack of a systematic and comprehensive needs analysis to inform EAP programs in Iran, the present study aimed to explore the EAP needs of students of knowledge and information science. Questionnaires, undergraduates' self-assessment, teachers' evaluation of undergraduates' language abilities, and semistructured interviews were used for eliciting data from the students (95 undergraduates and 18 graduates) and 17 teachers (9 ELT and 8 content teachers). Despite the differences between different groups of stakeholders' perceptions on undergraduates' present and target situation needs, the results showed that there are serious gaps between students' present language abilities and target situation academic English demands. Moreover, the students showed difficulty with all language skills, sub-skills, components, and study skills. Low level of language proficiency made undergraduates prefer an EGP-oriented EAP course devoid of specificity. The implications provided can be used for the renewal of EAP curriculum, course design, and materials development.
\end{abstract}

Keywords: English for Academic Purposes, Knowledge and Information Science, Needs Analysis, Present Situation Needs, Target Situation Demands

\section{Introduction}

\section{English for Academic Purposes and Needs Analysis}

Nowadays, English for Academic Purposes (EAP) has turned to have a recognized status in language instruction at Iranian universities (Atai \& Dashtestani, 2013). One can hardly find a figure from academia hesitating to recognize the indispensable role of EAP in the academic and professional success of students. Some measures may be taken in attempts to 
make the EAP course more relevant to learners' EAP needs. Content departments may employ subject-specific instructors believing that they are sufficiently familiar with the content, conventions and specific language of their particular fields. On many occasions, they may use materials developed by content specialists. A more common strategy used by EAP practitioners, is devising their own alternative informal curriculums to bring about relevance to their EAP learners' needs. What is missing is the "integral" and "obligatory" step in curriculum development known as needs analysis (Johns \& Price-Machadu, 2001, p. 49). Skipping a systematic needs assessment by Iranian curriculum developers (Atai, 2002; Atai \& Nazary, 2011) has resulted into the failure of the EAP stakeholders to identify "the gap between what learners already know, and what they need to know in order to study or work in their specific target environments" (Basturkmen, 2006, p. 15).

The effective and productive use of limited time (Basturkmen, 2006; West, 1994), can only be achieved through applying the syllabi and materials that have the highest relevance to the needs of specific groups of learners. This degree of relevance will not be brought about, unless a systematic needs assessment using a wide range of instruments is conducted to collect as much data as required on the learners' features, needs, and also the expectations of the target contexts. Otherwise, EAP learners would be less likely to succeed in introducing themselves as competent, skilled and qualified members of their desired academic communities.

In addition to syllabi and materials, teaching methodologies, and activities employed by teachers should be sensitive to the actual learners' needs and the communicative demands of academic situations (Belcher, 2006). Needs analysis also helps curriculum developers to specify a set of "micro skills from a general pool of skills" learning of which is most effective in facilitating learners' academic success (Basturkmen, 2006, p. 21).

The main goal of EAP which is helping learners to professionalize in academic communities can be adequately pursued through providing specific learners with "enough" and "the right English" (Hyland \& Hamp-Lyons, 2002, p. 2). The right English is the English specific to disciplines. Basturkmen (2006, p. 28) identifies the two elements of "language use" and "content" as specific to each academic community. She also recognizes "language system" and "language skills" - certain language forms and skills that occur or are used more frequently than other forms and skills but not "exclusive" to the same context, as specifiable elements of disciplinary languages. Systematic needs analysis is the key to determine the right English and hence achieving the EAP goal.

EAP courses differ from other language courses. Unlike other language courses, the EAP course is discipline-based (Atai \& Shoja, 2011), sensitive to specific groups of learners and their contexts (Johns \&Price-Machado, 2001). To put specificity and relevance into practice (Hyland, 2006), the EAP program requires integrating disciplinary contents, skills, language features and uses, and world views to help learners in the process of becoming competent members of their target communities. All these particularities and specificities oblige developing a profile of 
learners' abilities and the communicative demands of target academic contexts through a systematic and robust needs analysis.

Needs analysis includes specifying the type of language and communicative practices which are common and regular in target academic environments, assessing students' present competencies, and defining the objectives of their courses. The expectations and demands required by target contexts is referred to as target situation needs and the present knowledge of students is referred to as present situation needs (Belcher, 2006; Hyland, 2007).

In order to have a full and vivid picture of the conceptualization and the dimensions of EAP needs, the categorization offered by Dudley-Evans and St John is presented as a professional information about the learners (i.e., tasks and activities learners are/will be using English for target situation analysis and objective needs); b) personal information about the learners including factors which may affect the way they learn such as previous learning experiences, cultural information, reasons for attending the course and expectations of it, attitude to English wants, means and subjective needs; c) English language information about the learners (i.e., what their current skills and language use are - present situation analysis (otherwise the next step); $\mathrm{d}$ ) what the learners' lack: the gap between (c) and (a); e) language learning information on effective ways of learning the skills and language in stepd (learning needs); f) professional communication information: knowledge of how language and skills are used in the target situation - linguistic analysis, discourse analysis, genre analysis; g) what is wanted from the course? and, h) information about how the course- means analysis. (1998, p. 125)

From this sketch, it can be perceived that needs is an umbrella term (Hyland, 2006) including mainly students' present situation and target situation needs. Present situation needs, according to Hyland (2006, p. 74) includes assessing and understanding learners' proficiency levels, objectives, understanding of the course, abilities, and their knowledge of the content areas, academic genres and discourse demands. Target situation needs, on the other hand, can refer to discipline-specific "communication needs", focusing on describing discipline-based communicative practices, behaviors, and language uses. Furthermore, needs analysis includes, according to critical educationalists, "right analysis" which focuses on exploring the intentions of those who set the goals, the interests that are served and the ways of challenging the program (Benesh, 2001).

To sum it up, since an EAP course aims to help learners accomplish certain communicative needs in a particular academic context (Hyland \& Hamp-Lyons, 2002), the starting point in EAP curriculum development, from planning, implementation, evaluation to renewal is a systematic needs assessment (Flowerdew \& Peacook, 2001; Jordan, 1997). The findings of needs analysis provide the "foundation on which all other decisions are, or should be, made" (Belcher, 2006, p. $135)$.

\section{Knowledge and Information Science}

Knowledge and Information Science (KIS), previously known as 'Library and Information Science' in Iran, is the academic study of information and its resources including articles, 
books, encyclopedias, atlases, databases, etc. It professionally investigates the production, dissemination, selection, organization, evaluation and management of information and its carriers. There are different techniques and methods to each of them which are addressed and studied as well. Since the theories and practices of three disciplines of education, management and information technology are applied to KIS, it is known as a multidisciplinary field. The purpose of this discipline is to help learners transmit information in its various forms to its particular users, and make it possible for different users to use the information for a variety of purposes. Since this field is interdisciplinary and deals with information and its resources, the importance of competence in English and especially EAP seems considerable.

Inspecting the curriculum developed by the Ministry of Sciences, Research and Technology (MSRT, 2015), one can find that the included courses are 'general psychology', 'principles of sociology', 'principles of computer sciences', 'the history of science', 'word formation (English and Persian)', 'an introduction to press and media', 'an introduction to information and communication technology', 'an introduction to public relations', 'an introduction to databases' and 'an introduction to information management'. The nature of these courses all indicate that the role of language especially English in this discipline is a life-or-death issue. The course description provided by the ministry of sciences, research, and technology maintains that the purpose of the sub-course one (a two credit-course called EAP 1) is to enable learners to read and comprehend the academic texts of the field in English. The objective of the $2^{\text {nd }}$ and $3^{\text {rd }}$ sub-courses is making learners competent enough to read, comprehend and translate the academic texts of the field.

A study by Gaffas (2019) examined undergraduate students' perceptions about the effect of the general and specific courses they take in English on their academic language proficiency and usage. The study was done in a context where English was the medium of instruction. Surveys were used to collect data on students' views on what struggles they faced considering academic speaking, writing, reading and listening. Moreover, interviews and focus group discussions were utilized. According to the results, poor vocabulary knowledge was the students' greatest difficulty which caused them problems in all the four skills. Although the students appreciated the effects of the specific English courses in enhancing their knowledge of technical words, they found both general and specific courses to fail to increase their general proficiency in English. Romano (2019) evaluated the errors related to verb forms in the EAP writings of Chinese students examining the degree to which such errors stem from the absence of a similar structure in their first language (i.e., Chinese). Three forms were focused in this study including passives, tense/agreement, and modals. Data analyses showed that the majority of errors were related to omission and misuse. Tense/agreement errors were much higher compared to both passives and modals. The study showed that tense/agreement errors were more common since cognates do not exist in Chinese. The negative effects of transfer from the first language were also studied by Swaran-Singh, Jageer-Singh, Abd-Razak, and Ravinthar 
(2017). Their analyses of students' written samples focused on type and frequency of verb form errors. As for type, the errors involved four major areas including omission, addition, misformation, and ordering. And, for frequency, omission of the third person marker $(-\mathrm{s})$ was found to be the most common error. According to them, the frequent omission of inflection was most probably due to negative transfer from their first language.

\subsection{Purpose of the Study}

Studying an interdisciplinary and multidisciplinary field of study which deals with information of different types and sources, students of KIS have specific English needs. Their EAP course, if informed by systematic and appropriate needs analysis, can bring about success for them in their attempts toward professionalization. Surprisingly, the EAP curriculum developers have neglected the decisive role of needs analysis resulting in the failure of the EAP program (Atai, 2002). The present study, taking a triangulated approach (by sources and instruments) to data collection, aims at systematic analysis of the undergraduates' present situation needs and the demands of their target situation. The findings of this study will be used to build up a detailed profile of the related needs capable of being used as a base for evaluating and renewing the EAP curriculum and course. This paper reports a study which addressed the following questions:

1. What are the present situation academic English needs of Iranian undergraduate students of KIS?

2. What are the target situation academic English needs of Iranian undergraduate students of KIS?

3. Is there any difference between different groups on their perceptions of undergraduates' existing language abilities and the communicative demands of the target situation?

4. What are the major problems of EAP teaching and learning in Iranian Academic contexts?

\section{Method}

\section{Participants}

Ninety-five undergraduates of KIS, 18KIS graduates and 17 EAP teachers including nine ELT teachers and eight content instructors at four major universities of Iran including University of Tehran, Ferdowsi University, University of Tabriz and University of Zabol took part in this study. The undergraduates were from all four educational levels (i.e., freshmen, sophomores, juniors and seniors). The freshmen had not passed the EAP courses. Neither had they been enrolled in any of the EAP sub-courses (EAP course 1, 2, and 3). The sophomores, juniors and seniors either had passed one or two sub-courses or had been enrolled in one of the sub-courses of EAP (as the syllabus developed by the ministry of sciences, research and technology for the field of KIS specifies three 2-credit sub-courses for the main EAP course with each one offered in a separate semester). The nine ELT teachers were from English language departments (i.e., University of Tabriz and Zabol) and the eight content instructors were from the KIS departments (universities of Tehran, Tabriz and Zabol). 


\section{Instrumentation}

To have a more comprehensive understanding and assessment of learners' academic needs we adapted a triangulated approach to data collection both in terms of instruments and sources. That is, both quantitative and qualitative methods including questionnaires, selfassessment and semi-structured interviews were employed. Since the perceptions of learners' academic needs by different stakeholders reveal differing results due to their various experiences, expertise, levels of education, degree of involvement and understanding, triangulation of the study seems essential. A triangulated study collecting data from different sources through a wide range of instruments helps the researchers cross-validate the data and provide sound interpretation of the findings (Atai \& Shoja, 2011; Long, 2005).

\section{The Questionnaires}

The questionnaire was adapted from Atai and Shoja (2011), originally developed to assess the present situation needs and the target situation demands of EAP learners of computer engineering at Iranian universities. As Atai and Shoja (2011) explain, the questionnaires, informed by the latest insights from the needs analysis perspectives focusing on triangulation (Long, 1996), were carefully designed and developed to adequately collect both subjective and objective data (Basturkmen, 2010; Long, 2005).

The theoretical model, according to Atai and Shoja (2011), is a combined one comprising target situation analysis, present situation assessment and learners' lacks and wants (Dudley-Evans and St. Johns, 1998; Hutchinson and Waters, 1987, Hyland 2006, Jordan 1997, Robinson, 1991, West, 1994). The skill-based perspective informed the language and language learning model. Each item of the questioner was developed in a way to correspond to a particular category of academic needs and demands. Again, to avoid misinterpretation, like Atai and Shoja (2011),the questionnaires were drafted in respondents' native language (i.e., Persian).

An open-ended question was added to the questionnaires of undergraduate and graduate EAP learners to write as many problems as they think are common to EAP learning and teaching in Iranian context. The elicited information through this open ended question was used to be compared to the reactions of ELT and content teachers to the same problems and issues collected through semi-structured interviews. In addition, five other questions were included in the undergraduates' questionnaires to investigate further the main issues explored in questionnaires and interviews.

\section{Proficiency-assessment Tests and Scales}

To explore present situation needs further, we employed self-assessment test comprising thirty-two items and incorporated it into the questionnaire of the undergraduates. A similar section consisting of the same number of items was incorporated into the questionnaire of the ELT teachers asking them to evaluate the general language proficiency levels of EAP 
students. For the purpose of further assessing learners' general language proficiency, another self-assessment section with a six-point scale adopted from the Common European Framework of Reference was included in the undergraduate students' questionnaire to elicit their own assessment of their language proficiency. The same scale with some modification in language was administered to the content teachers asking them to decide on the percentage of their learners fitting each category of proficiency.

\section{Semi-structured Interviews}

Semi-structured interviews, providing in-depth data, were used to elicit further information from the two professional stakeholders including ELT and content teachers. The elicited information was used to "cross-check" the participants' perceptions on present situation needs and target situation expectations explored through questionnaires and proficiency assessment tests (Atai \& Shoja, 2011). The other purpose was to elicit ELT and content teachers' reactions to problematic and challenging areas of foreign language education in general and EAP education in particular.

The interview protocol was developed based on the theoretical framework adapted in the study and derived from the feedback of a panel of EAP and content teachers. The questions included in the interview protocol reflected the issues investigated through different sections of questionnaires and also other related language education issues common to Iranian EFL context.

\section{Procedure}

Data collection began with administering questioners to undergraduates in November 2013. To ensure that the students take the questionnaires more seriously and to maximize the return rate, they were administered during the classroom meetings. Then, the other groups of stakeholders were asked to complete the corresponding questionnaires. The Semi-structured interviews, ranging from 15 to 20 minutes, were conducted after the completion of the questionnaires by the instructors.

\section{Data Analysis}

In addition to descriptive statistics, inferential statistics including two Mann-Whitney U Tests and two Kruskal-Wallis Tests using SPSS (v. 17) were run. The first Mann-Whitney U test was conducted to test the difference between undergraduates' and ELT teachers' perceptions on learners' existing language proficiencies. To compare the difference between two groups of stakeholders on individual items we conducted the second one. The first Kruskal-Wallis Test was used to check whether the differences between different groups' perceptions on target situation demands are statistically significant or not. To probe further the difference, the second KruskalWallis Test comparing their perceptions on individual items of this section was conducted. The data elicited through interview was subjected to descriptive and content analysis. 


\section{Results}

\section{Present Situation Needs}

The data obtained through self-assessment section of the undergraduate questionnaire indicated that they have serious difficulty with 'note taking from lectures related to the field' (91.5\% — as they chose either I can't do it at all or I can do it with a lot of efforts), 'participating in international events' (86.2\%), 'writing scientific articles' $(85.2 \%)$, 'critical reading' (82.2\%), 'comprehending English lectures on knowledge and information science' (83.9\%), 'asking questions in seminars related to the field (80\%), 'preparing English slides' (80\%), 'reading and comprehending subject specific texts in English' (78.9\%), 'writing summary of subject specific texts (78.7\%), 'writing homework and assignments in English' (73.7\%), and 'taking class examination in English' (73.7\%). They also reported difficulty with 'taking notes while reading', 'distinguishing important point from unimportant points', 'understating relationship between ideas, cohesive devices', 'understanding teachers slides in English', 'guessing the meaning of unknown words from context', 'guessing the meaning of unknown words from prefixes and suffixes, 'using monolingual technical dictionaries (English- English)', translating technical texts from Persian to English and vice versa', 'knowledge of grammar', 'writing email to teachers and field experts' and 'pronunciation'. 'Using bilingual general dictionaries from English to Persian', 'using bilingual general dictionaries from Persian to English' and 'using bilingual technical dictionaries from English to Persian' were the areas they had the least difficulty.

The second group of stakeholders, ELT teachers, believed that EAP students have difficulty with all language skills, sub-skills and language components. Their responses assigned the most difficulty with 'writing scientific articles' (100\%), 'understanding the relationship between ideas, and cohesive devices' (100\%), 'knowledge of technical vocabulary' (88.9\%), 'writing homework and assignments in English' (77.8\%), 'using monolingual technical dictionaries-English to English' (77.8\%), 'translating technical texts from Persian to English' (77.8 \%), 'critical reading' $(66.7 \%)$, 'writing summary of subject specific texts' (66.7\%), 'taking class examination in English' (66.7\%), 'comprehending English lectures on knowledge and information science' (66.7\%), knowledge of grammar' (66.2\%) and 'pronunciation' (66.7\%).

The information elicited through interviews from EAP teachers (Both ELT and content teachers) closely corresponded to the findings of questionnaires. That is, they believed that undergraduates have difficulty in reading comprehension, writing, vocabulary, translation, sentence structure and grammar.

In order to check for differences between two groups of stakeholders, undergraduates and EAP teachers, on their assessment of learners' present language competence and needs (research question 3), a Mann-Whitney $U$ test was run. A summary of the test result is presented in Table 1. As shown, the difference between the groups on evaluation of EAP learners' present situation needs are not statistically significant $(p=.08)$. 
Table 1

Results of Mann-Whitney U Test for differences between undergraduates' and ELT teachers' perceptions of EAP learners' present situation needs

\begin{tabular}{lllllll}
\hline & Respondents & $\mathrm{N}$ & Mean rank & Sum of ranks & Mann-Whitney & Asymp. Sig. \\
\hline PSA & Undergraduates & 91 & 52.10 & 4741.00 & 264.000 & .08 \\
& ESP teachers & 9 & 34.33 & 309.00 & & \\
Total & 100 & & & & \\
& & & & &
\end{tabular}

To probe further, the differences between perceptions of two groups on individual items were examined running another Mann-Whitney U Test. A summary of the results provided by the second Mann-Whitney $U$ test is presented in Table 2. As can be seen, the difference between the two groups on Items3 (scanning the text), 9 (writing summary of subject specific texts), 13 (preparing English slides), 14(writing scientific articles), 15 (writing homework and assignments in English), 26 (translating technical texts from English to Persian), and 32 (pronunciation) were statistically significant.

Table 2

Results of Mann-Whitney U Test for differences between undergraduates' and ELT teachers' perceptions on Individual items of EAP learners present situation needs

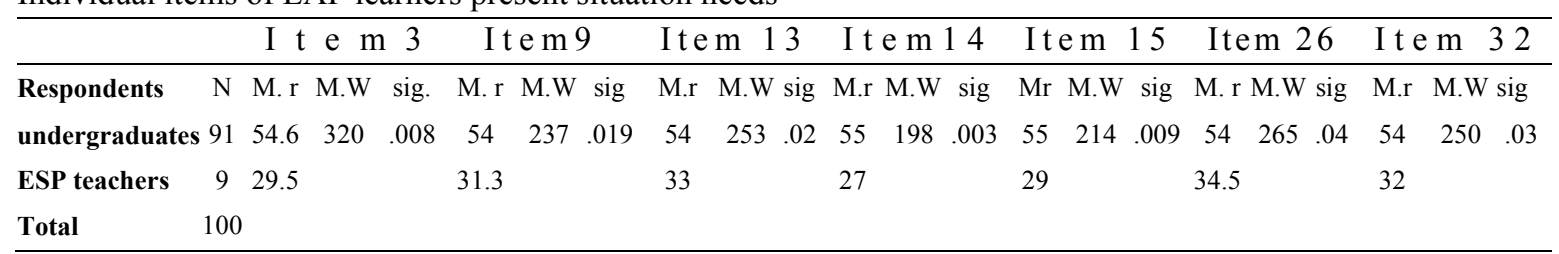

As mentioned in instrumentation section, we used a six-band scale and incorporated it into the questionnaires of undergraduates, ELT and content teachers for the purpose of assessing learners' language proficiencies. The undergraduates were asked to specify their own proficiency levels. Analysis of the results showed that $46.65 \%$ fit in level A1,34.78\% in $\mathrm{A} 2,13.04 \%$ in $\mathrm{B} 1,5.43 \%$ in $\mathrm{B} 2,1.08 \% \mathrm{in} \mathrm{C} 1$, and none of them recognized himself/herself fitting in level C2. The results of undergraduates' self-assessment indicated that $81 \%$ of them are placed at the beginning or elementary levels of general language proficiency in the scale.

The results obtained from ELT teachers on placing students at six levels of proficiency were as follow; they placed $71.83 \%$ of undergraduates at level A1, $16.09 \%$ at A2, $9.19 \%$ at $\mathrm{B} 1,2.87 \%$ at $\mathrm{B} 2$, and they said that none of them can fall at $\mathrm{C} 1$ or $\mathrm{C} 2$. The reaction of this group of EAP stakeholders indicated that a great majority of EAP learners $(71.83 \%)$ fall only at level A1 which is the weakest level of general language proficiency (i.e., beginners).

The same evaluation was performed by content teachers. The results of their evaluation said that $56.25 \%$ of the students are at level A1, 28.75\% at A2, $11.87 \%$ at B1, $2.50 \%$ at B2, $0.62 \%$ at 
$\mathrm{C} 1$, and none was qualified to fit at level C2. In short, their evaluation indicated that $84.25 \%$ of the students are beginnersor at elementary level. The results of undergraduates' self-assessment and content teachers' evaluation were approximately identical.

\section{Target Situation Demands}

The first sections of the questionnaires administered to all four groups of stakeholders help the researcher to investigate the target situation demands of undergraduate EAP students. It consisted of 20 items associated with different language skills, sub skills and language components that EAP learners require to introduce themselves as an expert member of the target community. They thought that 'knowledge of general vocabulary' $(78.5 \%)$, 'translating technical texts from Persian to English' (73.9\%), 'knowledge of technical vocabulary' (73.4\%), 'writing email to teachers and field experts' $(71.6 \%)$, 'using bilingual technical dictionaries-English to Persian' (68.4\%), 'knowledge of grammar' (66.4\%), 'pronunciation' (63.2\%), 'using bilingual general dictionary, Persian-English' (61.1\%), and 'using internet to do research' (60\%) were the most needed language skills and sub-skills, language components and study skills for their academic success in the future. They also found the other (sub)skills and components important. The four items they perceived to be less important as the target situation expectations included 'taking class examination in English' (only 7.4\% chose very important), 'preparing English slides' (11.7\%) and 'writing homework and assignment in English' (11.7\%).

Content teachers' assessment of target situation needs indicated that 'knowledge of general vocabulary' (100\%), 'translating technical texts from English to Persian' (100\%), 'translating technical texts- Persian to English (100\%), 'writing email to teachers and field experts' (100\%), 'comprehending English lectures on knowledge and information science' (87.5\%), 'using bilingual technical dictionaries, English to Persian' (87.5\%), 'participating in international events' (87.5\%) and 'reading subject specific texts in English' (75\%) were the more important skills. They also thought that 'writing homework and assignments in English' (38.3\%), 'preparing English slides' (37.3\%) and 'taking class examination in English' (50\%) were less important among the 20 items.

ELT teachers were the third group whose opinions on the target situation demands and expectations were considered. The results of their reactions showed that they found all language skills, sub-skills, language components, and study skills important. They evaluated 'reading subject specific texts in English' (100\%), 'knowledge of technical vocabulary' (100\%), 'writing email to teachers and field experts' $(100 \%)$, 'knowledge of general vocabulary' $(88.9 \%)$, 'using monolingual technical dictionaries-English to English' (88.8\%), 'using bilingual technical dictionaries English- Persian' (88.8\%), 'translating technical texts' (77.8\%), 'understanding English lectures on knowledge and information science' (77.7\%), and 'understanding teachers slides' as more important than others. Although their responses showed that all skills and components are important, their assessment reported that 'writing homework and assignments in English' (25\%) and 
'writing scientific articles' (50\%) were less important.

The results of interviews with content teachers and ELT teachers showed that both groups of instructors find reading skills most needed. They also focused on the need for improvement of writing skills, vocabulary knowledge, grammar, sentence structure and translation. Content teachers said that half of the needed context-specific texts are available to them and most of them prefer to use these original texts instead of translated ones.

Graduate students' assessment of target situation demands revealed that, like other groups of stakeholders, they found all skills, sub-skills and language components important. The results indicated that undergraduates need 'knowledge of general vocabulary' (100\%), knowledge of technical words (94.4\%), 'writing email to teachers and field experts' (88.9\%), 'knowledge of grammar' (88.9\%), reading subject-specific texts in English (77\%), 'translating technical texts from Persian to English' (88.8\%), 'translating technical texts from English to Persian' (77.8\%), 'using bilingual technical dictionariesEnglish to Persian' (83.4\%) more than others. They perceived that taking class examination in English (33.3\%), and 'participating in international events' (38.9\%) were less important.

To compare the perceptions of four groups of stakeholders on target situation demands and expectations, two Kruskal-Wallis tests were run to answer the question whether the differences between stakeholders' perceptions on target academic situation is statistically significant or not, and which items signals a significant difference. Table 3 shows that the differences between the perceptions of four groups on target situation needs is statistically significant ( $p=.016$; an inspection of the mean ranks for four groups says that ELT teachers (81.28) reported the highest rank with the undergraduates (55.15) indicating the lowest rank).

Table 3.

Results of Kruskall Wallis Test for differences between four groups' perceptions of EAP learners' target situation needs

\begin{tabular}{lllllll}
\hline & Respondents & $\mathrm{N}$ & Mean rank & Sum of ranks & Chi-Square & Asymp. Sig. \\
& Undergraduates & 88 & 52.15 & 4741.00 & 10.316 & .016 \\
TSA & Graduates & 17 & 77.32 & 309.00 & & \\
& ELT teachers & 9 & 81.28 & & \\
& Content teachers & 8 & 75.44 & 309.00 & & \\
& Total & 122 & & & \\
\hline
\end{tabular}

To further check the differences between perceptions of the groups, we ran another Kruskall-Wallis Test for individual items. The results (Table 4) suggested that the differences between four groups of stakeholders on Items $1(p=.000$; reading subject specific texts in English), 7 ( $p=.01$; comprehending English lectures on knowledge and information science), and 19 ( $p=.000$; writing email to teachers and field experts) were 
statistically significant.Other items did not indicate any significant differences.

The mean ranks for four groups on items says that the EAP teachers reported the highest (108) and the undergraduates the lowest (51.78) for Item 1; content teachers reported the highest (94.94) with the undergraduates reporting the lowest (59.27) mean rank for Item 7; and, EAP teachers reported the highest (79. 78) and undergraduates the lowest (61.52) mean rank for Item 19.

Table 4.

Results of Kruskall Wallis Test for differences between four groups' perceptions on Individual items of EAP learners' target situation needs

\begin{tabular}{lllllllllllllllll}
\hline & $\mathrm{I}$ & $\mathrm{t}$ & $\mathrm{e}$ & $\mathrm{m}$ & $\mathrm{l}$ & $\mathrm{I}$ & $\mathrm{t}$ & $\mathrm{e}$ & $\mathrm{m}$ & & $\mathrm{I}$ & $\mathrm{t}$ & $\mathrm{e}$ & $\mathrm{m}$ & 1 & 9 \\
\hline Respondents & No. & M. $\mathrm{r}$ & Chi. & Sig. & No. & M.r & Chi. & Sig. & No. & M. r & Chi. & Sig. \\
\hline Undergraduates & 95 & 57.7 & 205 & .000 & 94 & 59.2 & 10.99 & .014 & 95 & 58 & 18.06 & .000 \\
Graduates & 18 & 78.2 & & & 18 & 73.3 & & & 18 & 78.7 & & \\
ELT teachers & 9 & 108 & & & 9 & 81.6 & & & 9 & 99 & & \\
Content teachers & 8 & 80 & & & 8 & 94.9 & & & 8 & 86.2 & \\
Total & 130 & & & & 129 & & & & & 130 & & & \\
\hline
\end{tabular}

The third section incorporated into the questionnaires of graduate students and ELT teachers was a question exploring the two groups' views on the priority of language skills and components as the content of the EAP course. They were asked to choose the four skills and components (out of eight alternatives) they think should be focused in the EAP course. The results indicated that undergraduates evaluated all skills and components important. The data reported that they prefer translation, vocabulary, pronunciation and grammar over other ones. The responses elicited from ELT teachers indicated their preference for reading, writing, grammar and vocabulary.

In response to the question exploring their preference of ESP-oriented or EGP-oriented EAP course, only $33.68 \%$ of learners preferred ESP-oriented course while content teachers and EAP instructors shared the same idea in taking a totally different path with undergraduates and believed that EAP course should be ESP-oriented $(100 \%$ of both groups chose ESP).

As mentioned above, the EAP course for undergraduate students is a six-credit course (with three two-credit courses each one being offered in separate semesters). The results showed that $70.21 \%$ of undergraduates believed that the number of credits is adequate. However, $88.88 \%$ of content teachers and $100 \%$ of ELT teachers believed that the number of credits and amount of time allocated to EAP instruction is not adequate. They suggested that an EAP course of 8 to 12 credits would be more satisfying. 


\section{The Major Problems of EAP Teaching and Learning}

To further investigate the respondents' reactions and to have a comprehensive understanding of the challenges of ESP education in Iran, undergraduates and graduates prepared a written report of their perceptions to the open-ended question incorporated into their questionnaires. EAP teachers also mentioned the main challenges when they were being interviewed. The major challenges from the undergraduates' perspective include the followings.

First, there is no opportunity to put in use (in daily activities) whatever you learn during classroom instruction, and this is more serious about English vocabulary which is highly elusive $(13.30 \%)$. Second, the program of foreign language teaching and learning is not systematic especially in the first years of language learning which ultimately leads into poor mastery of general English (100\%). Next, teachers either are non-qualified or employ ineffective and out-of-date teaching methodologies, activities and practices (16.66 \%). Fourth, the governments' attention to English education is inadequate and ESP program is not systematic and realistic (33\%). Fifth, the number of credits and time allocated to EAP instruction is inadequate $(10 \%)$. Sixth, teaching and learning materials are not fruitful enough to foster language and skills development needed for the success of language learners in meeting the demands of target academic context (12.22\%). Seventh, schools and universities do not offer good facilities and there is no intention to upgrade the existing facilities especially when the EAP course is very crowded $(5.55 \%)$. Eighth, there is not satisfying cooperation between instructors and learners. $(2.22 \%)$. Ninth, much attention is put on the quantity in teaching rather than quality(1.11\%). Finally, learning English, especially its vocabulary, pronunciation and grammar is difficult $(20 \%)$.

Undergraduates believed that low level of proficiency, lack of useful teaching and learning materials, especially multimedia ones, inadequate time of instruction, unsystematic language teaching program from the first years of foreign language instruction, ineffective and out of date teaching methodology and practices employed by teachers, over-reliance on content teachers for EAP teaching, heterogeneous language classrooms regarding learners' general English proficiency, lack of teachers' seriousness about EAP courses and segregated skill teaching are the major problems of EAP education in Iran.

Content teachers focused on low level of general English proficiency on entry to the EAP course, lack of opportunity to practice learned materials in out of class contexts, ineffective methods and practices of teaching, negative attitudes towards language teaching program and lack of sufficient self-study. They also focused on the prohibiting role of discouragement among learners as a result of low proficiency.

ELT teachers shared the same idea with other stakeholders focusing on the impeding role of learners' low proficiency on entry to EAP course. They also stated that the idealistic and unrealistic goals of language teaching program, students' unfamiliarity with study skills, lack of motivation among learners and lack of a systematic program to improve the quality of language education pose serious challenges to the EAP Education. 
When asked whether they prefer ELT teachers or subject specific instructors to run their courses, $50.53 \%$ of the undergraduates preferred ELT teachers. Their perception on the best time of taking the EAP course indicated that $55.59 \%$ prefer EAP course to be offered in the second half of their four-year career.

ELT teachers and content teachers in response to the question asking them on the amount of L1 (Persian) they incorporate into L2 instruction mentioned that most of the time they have to incorporate L1 into target language instruction. Content teachers reported that using English, surprisingly, is limited only to reading subject-specific texts. They insisted that for other teaching activities such as giving instruction, direction and rubrics of tasks, explanation of points or ideas and translating the texts they have to resort to their first language. ELT teachers, referring to low level English proficiencies of EAP learners and the resulting discouragement, cited their need to use L1 to fulfill the objectives of the course and keep learners motivated.

\section{Discussion}

The findings of the study showed that the four participating groups identified all language skills, sub-skills, components, and also the specified ways of acquiring required language as important, but they gave different weighting to them. This variation can be explained by Hyland's (2006, p. 74) argument that needs "mean different things to different participants". Of the conspicuous points in their responses is that all groups gave a considerably higher weighting to the 'knowledge of general and technical vocabulary' and 'grammar'. As the knowledge of vocabulary and grammar is a requirement for reading comprehension and, given the main objective of EAP program in Iran which is said to be bridging "the gap between the students' general reading competence and their ability to read authentic discipline-specific texts in their real authentic world" (Atai \& Tahririan, $2003,4)$, it can be argued that the respondents are more concerned about the requirements of reading skills than the skill itself.

While EAP needs are more concerned with "communication rather than language" (Hyland, 2007, p. 397), the participants in this study tend to see EAP needs as language rather than communication. The EAP teachers showed a greater care about communicative and real-life tasks commonly encountered in target professional contexts.

Reading and translation were among the most important skills in the view of all participants especially EAP teachers since they ranked 'reading subject-specific texts in English' as the first one. The results of the interviews with EAP and content teachers also confirmed this focus. There was a statistically significant difference between participants' perceptions on the importance of reading skills. The EAP teachers were more heedful to reading skill as a major skill including other sub-skills and language components, but other groups especially undergraduates were more concerned about the knowledge of grammar and vocabulary.

Regarding to the orientation of EAP course, the difference between undergraduates' 
view with those of other groups may be justified by their level of understanding and familiarity with the specificity of their target discipline and context. The undergraduates' focus on the EGP orientation shows that their unfamiliarity with target situation and its demands and expectations in terms of specific registers, discourses, and genres have made them think that the knowledge of general English can guarantee their proficiency and mastery of EAP courses. The instructors' focus on ESP orientation indicates their insistence on the idea that EAP learners need discipline-specific EAP courses to "gain fluency in the conventions of English language academic discourse" (Hyland \& HampLyons, 2002, p. 1).

The difference between perceptions of undergraduates and instructors on the adequacy of the number of credits and amount of time allocated to EAP instruction can be explained with the hard time language learners experience in EAP courses given their low level of proficiency, their limited understanding of specificity of EAP courses mentioned above and their lack of motivation.

Relevant to the major challenges of EAP teaching, it was found that low level of proficiency with the resulting discouragement and the lack of opportunity to put in use the learned language out of classroom are the most serious problems. That is, in EAP courses a positive "transfer climate", a climate which is essential for transferring learning, is missing (James, 2010, p. 133). Given the fact that "teaching needs to provide learners with opportunities to use whatever linguistic resources they have at their disposal" (DudleyEvans and Johns, 1998, p. 124), this lack prohibits them from internalizing and personalizing the instructed language.

The problem of low quality teachers and the employment of ineffective and out of date teaching methodology can be explained by Hyland and Hamp-Lyons' (2002, p. 10) argument that "EAP teachers are frequently employed as vulnerably short-term instructors", mainly lacking the "professional qualifications to handle the typical features" of the EAP education(Long, 2005, p. 21).

Undergraduates' objection to the use of ineffective teaching and learning ESP materials points to the need of producing and adapting materials that are capable of "meeting the specific needs identified ... to cope with unfamiliar subject matter and even language use" (Belcher, 2004, p. 166). Given the specificity of the EAP course and their short-term period, producing, adapting and using materials capable of involving learners both cognitively and affectively seems necessary (Tomlinson, 2012). Such a goal can be achieved only if materials development is research-lead drawing on the findings of systematic needs analyses and recent genre, corpus and discourse studies (Harwood, 2005).

Despite the facilitative role of careful and judicious use of L1 for foreign language instruction (Cook, 2001; Eschweers, 1999; Turnbull, 2001), the use of L1 (Persian) to the exclusion of target language has a detrimental influence on EAP instruction (Nation, 2007) especially when the overreliance on L1, as it is common to our teachers, is because of learners' low level of language proficiency (Cummins, 2007; Dujmovic, 2007). 
The results of undergraduates' self-assessment showed that they had serious difficulty with both language and learning skills. That is, they need to improve their abilities in both receptive and productive skills and also be equipped with learning skills and strategies such as academic reading comprehension skills, writing skills and strategies. The findings were in line with the results of the current studies on EAP courses in Iran (e.g., Atai, 2002; Atai \& Nazari, 2011; Atai \& Shoja, 2011). Low level of language proficiency on the entry to EAP courses seems to have turned EAP courses into a common language course only different in terms of including technical vocabulary items and subject-specific texts rarely covered in the course (Atai \& Fathi-Majd, 2014). This obsession with general English has distracted EAP practitioners' and learners' attention from concentrating on and covering the conventions and regularities unique to their disciplines such as genre, discourse, and metadiscoursal features.

\section{Conclusion}

It can be concluded from the findings of the study that dissatisfaction with EAP courses for undergraduates of KIS signals a mismatch between the idealistic goals set by the policy makers and the actual course outcomes. The most serious danger threatening the whole program is that the EAP course does not capture the essence of specificity by the learners and instructors being preoccupied with the problems and complications pertaining to general language proficiency. The problem of general proficiency and basic academic skills cannot be dealt with in EAP courses as the objectives of courses are different. Policy makers, course designers and practitioners have to take operational measures to improve students' language proficiency and basic academic skills needed on the entry to EAP courses.

We can also draw the conclusion that the current EAP courses are not context, learner and discipline-sensitive as they are not informed by the findings of systematic needs analyses. Neither are they enriched by the findings of the current genre, discourse and corpus studies. Deprived of the cooperative works of all groups of stakeholders, the goals have been set irrespective to students' true levels of proficiency and familiarity with academic skills, local teaching constraints and the facilities available. Given the principle that "EAP has a commitment to research-based language education" (Hyland \& HampLyons, 2002, p. 1), the study recommend that EAP course designers renew the courses aiming to design discourse, genre and needs oriented ones.

Regarding teaching materials and considering the necessity of existence of a match between teaching content, knowledge, learning and study needs of EAP learners, it is recommended that materials developers draw on the findings of needs analyses and contribution of all stakeholders to produce materials relevant and catering to the actual learners' needs.

The study was restricted in two major ways. First, the quality of stakeholders' cognitions on and understanding of EAP goals and principles were taken for granted. If so, 
the results may have minimum, if any, contribution to the improvement of the whole program. Future studies may systematically consider the limitations of participants' cognition into consideration in their needs analysis studies. Second, the study was limited by the small number of EAP teachers, both ELT and content instructors. Further studies may be needed to elicit the perceptions of larger groups of EAP teachers with differing degrees, ranks, and EAP teaching experience.

\section{Acknowledgements}

The conduction of this study would not have been possible if not for the help of many colleagues, teachers, and people working at different offices. I would like to express my sincere gratitude for their help.

\section{References}

Atai, M. R. (2002). EAP curriculum planning in Iran: An incoherent educational experience. Special Issue of the Journal of Faculty of Letters and Humanities, Teacher Training University, 9, 17-34.

Atai, M. R., Dashtestai, R. (2013). Iranian English for academic purposes (EAP) stakeholders' attitudes toward using the internet in EAP courses for civil engineering students: Promises and challenges. Computer Assisted language Learning, 26(1), 21-38.

Atai, M. R., \& Nazari, O. (2011). Exploring reading comprehension needs of Iranian EAP students of health information management (HIM): A triangulated approach. System, 39, pp. 30-43.

Atai, M. R.,\&Shoja, L. (2011). A triangulated study of academic language needs of Iranian students of computer engineering: Are the Courses on Track? RELC Journal, 43(3), 305-323.

Atai, M.R., \&Tahririan, M.H. (2003). Assessment of the status of ESP in the current Iranian higher educational system. In: Proceedings of LSP; Communication, Culture, and Knowledge Conference. University of Surrey, Guilford, UK.

Basturkmen, H. (2006). Ideas and options in English for specific purposes. London: Routledge.

Belcher, D. D. (2004). Trends in teaching English for specific purposes. Annual Review of Applied Linguistics, 24, 165-186.

Belcher, D. D. (2006). English for specific purposes: Teaching to perceived needs and imagined futures in worlds of work, study and everyday life. TESOL Quarterly, 40, 133-156.

Benesch, S. (2001). Critical English for academic purposes: theory polices and practice. Malwah, New Jersy: Lawrence Erlbaum Associates.

Berwick. R. (1989). Needs assessment in language programming: from theory to practice, In R. K. Johnson (ED). The second language curriculum (pp. 48-62). Cambridge: Cambridge University Press.

Brindley, G. (1989). The role of needs analysis in adult ESL programme design, In R. K. Johnson (Ed). The second language curriculum (pp. 63-77). Cambridge: Cambridge University Press.

Cook, V. (2001). Using the first language in the classroom. Canadian Modern Language Review 57(3), 402-423.

Cummins, J. (2007). Rethinking monolingual instructional strategies in multilingual classrooms. Canadian Journal of Applied Linguistics, 10, 221-241.

Cunningsworh, A. (1995). Choosing your course book. Oxford: Heinemann.

Dujmovic, M. (2007). The use of Croatian in the EFL classroom. Metodicki Obzori 2(1), 91-100. 
Dudley-Evans, T. \& St John, M. J. (1998). Developments in English for specific purposes. Cambridge: Cambridge University Press.

Flowerdew, L. (2005). Integrating traditional and critical approaches to syllabus design: The 'what', the 'how' and the 'why?' Journal of English for Academic Purposes, 4, 135-147.

Flowerdew, J. \& Peacock, M. (2001). Issues in EAP: a preliminary perspective. In J. Flowerdew \& M. Peacock (Eds.), Research perspectives on English for academic purposes (pp. 8-24). Cambridge: Cambridge University Press.

Gaffas, Z. M. (2019). Students' perceptions of the impact of EGP and ESP courses on their English language development: Voices from Saudi Arabia. Journal of English for Academic Purposes, 42, 1-13. doi:10.1016/j.jeap.2019.100797

Johns, A. M. \& Price-Machada, D. (2001) 'English for Specific Purposes (ESP): Tailoring Courses to Students' Needs - and to the Outside World' in M. Celce-Murcia (ed.) Teaching English as a Second or Foreign Language, $3^{\text {rd }}$ ed, (pp. 43-54).Boston: Heinle and Heinle.

Jordan, R. R. (1997). English for academic purposes. Cambridge: Cambridge University Press.

Harwood, N. (2005). What do we want EAP teaching materials for? Journal of English for Academic Purposes, 4, $149-161$.

Hutchinson, T. \& Waters, A. (1987). English for specific purposes. Cambridge: Cambridge University Press.

Hyland, K. (2002). Specificity revisited: How far should we go now? English for Specific Purposes, 21, 385-395.

Hyland, K. (2006). English for academic purposes: An advanced resource book. London: Routledge.

Hyland, K. (2007). English for Specific Purposes: Some Influences and Impacts. In J. Cummins \& C.

Davison (Eds.). International handbook of English language teaching (vol. 11). Springer Science \& Business Media.

Hyland, K. \& Hamp-Lyons, L. (2002). EAP: Issues and directions. Journal of English for Academic Purposes, 1, $1-12$.

James, M. A. (2010). Transfer climate and EAP education: Students' perceptions of challenges to learning transfer. English for Specific Purposes, 29, 133-147.

Long, M. H. (1996). The role of the linguistic environment in second language acquisition. In W. C. Richie \& T. K. Bhatia (Eds.), Handbook of second language acquisition (pp. 413-468). San Diego: Academic Press.

Long, M. H. (2005a). Methodological issues in learner needs analysis. In Long, M. H. (Ed). Second language needs analysis (pp. 19-76). Cambridge: Cambridge University Press

Long, M.H., (2005b). Second Language Needs Analysis. Cambridge: Cambridge University Press

Munby, J. (1978). Communicative syllabus design. Cambridge: Cambridge University Press

Nation, P. (1997). L1 and L2 Use in the Classroom: A Systematic Approach. TESL Reporter, 30(2), 19-27.

Robinson, P. C. (1991). ESP today: A practitioner's guide. New York: Prentice Hall International.

Romano, F. (2019). Grammatical accuracy in EAP writing. Journal of English for Academic Purposes, 41, 1-31. doi:10.1016/j.jeap.2019.100773

Schweers, W. Jr. (1999). Using L1 in the L2 classroom. English Teaching Forum, 37(2), 6-9.

The ministry of science, research and technology (MSRT) (2015). The syllabus for undergraduate students of knowledge and information science. Tehran: MSRT.

Swaran-Singh, C. K., Jageer-Singh, A. K., Abd-Razak, N. Q., and Ravinthar, T. (2017). Grammar errors made by ESL tertiary learners in writing. English Language Teaching, 10(5), 16-27.

Tomlinson, B. (2012). Materials development for language learning and teaching. Language Teaching 45 (2,) 143179. 
Turnbull, M. (2001). There is a role for the L1 in second and foreign language teaching, but . . The Canadian Modern Language Review, 57, 531-540.

West, R. (1994). Needs analysis in language teaching. Language Teaching Abstracts, 1-19. 